\title{
RADIOCARBON PRODUCTION BY THE GAMMA-RAY COMPONENT OF SUPERNOVA EXPLOSIONS
}

\author{
PAUL E. DAMON, ${ }^{1}$ DAI KAIMEI, ${ }^{1,2}$ GRANT E. KOCHAROV ${ }^{3,4}$ IRINA B. MIKHEEVA ${ }^{1,3}$ and \\ ALEXEI N. PERISTYKH ${ }^{1,3}$
}

\begin{abstract}
We selected SN1006, the brightest and closest to Earth of all supernovas historically observed, for a study of ${ }^{14} \mathrm{C}$ production by $\mathrm{e}^{-}, \mathrm{e}^{+}$-bremsstrahlung cascades initiated by hard $\gamma$ rays $(>10 \mathrm{MeV})$ from that event. During the cascade, bremsstrahlung energies eventually fall within a giant $(n, \gamma),(n, 2 \gamma)$ cross-section, peaking at $23 \mathrm{MeV}$ and approaching effectively zero below $10 \mathrm{MeV}$ and above $40 \mathrm{MeV}$. The neutrons are absorbed primarily in the reaction ${ }^{14} \mathrm{~N}(\mathrm{n}, \mathrm{p})^{14} \mathrm{C}$. Cellulose from single-year tree rings from $A D 1003$ to $A D 1020$ was measured to determine $\Delta^{14} \mathrm{C}$. Three years after the first visual observation of SN1006, $\Delta^{14} \mathrm{C}$ rose and remained above pre-AD 1009 values until AD 1018. Comparison of the 7 years before AD 1009 with the 9 years following show an average increase of $6.1 \pm 1.6$ (s.d.)\%o (significant at the $99.6 \%$ confidence level). Such a pulse of ${ }^{14} \mathrm{C}$ requires a total production of neutrons of $17.1 \times 10^{7} \mathrm{n} \mathrm{cm}^{-2} \mathrm{e}$, implying an input of $11.3 \times 10^{4} \mathrm{ergs}^{-2} \mathrm{e} \gamma$-ray energy. This requires the total supernova $\gamma$-ray energy $(>10 \mathrm{MeV})$ to have been $1 \times 10^{50} \mathrm{ergs}$.
\end{abstract}

\section{INTRODUCTION}

Supernova explosions occur at the rate of about two per century in a standard galaxy whose light is equal to $10^{10}$ Suns, assuming that the Hubble constant is $100 \mathrm{~km}^{-1} \mathrm{~s}$ per Mpc (Murdin 1990). In our galaxy, seven supernovas have been visually observed since the 2 nd century AD. There are also two optical supernova remnants and one that is only a radio remnant, for a total of 10 in 18 centuries, or a little more than one every other century (Table 1, Fig. 1). Supernovas are the source of not only visible, but also ultraviolet and infrared light, as well as neutrinos and cosmic rays. Cosmic rays include nuclides (ionized hydrogen and helium as well as heavier elements), $X$ rays and $\gamma$ rays.

Supernovas are a subject of considerable interest to laymen and philosophers as well as scientists. Unfortunately, the window of observation of supernova events occurring within our galaxy has been quite narrow. Light from the first historically recorded event arrived in AD 185 (Table 1). Light from Kepler's supernova arrived in AD 1604, a few years before the invention of the telescope. Thus, instrumental observations date back less than four centuries. Optical, X-ray and radio observations have allowed identification of 40 remnants within our galaxy. Fortunately, production of cosmogenic isotopes by cosmic rays opens a wider window. For example, ${ }^{10} \mathrm{Be}$ from natural archives such as polar ice (Raisbeck et al. 1987) and ocean sediments (McHargue, Damon and Donahue 1995) extends the window of observation back hundreds of thousands of years. ${ }^{14} \mathrm{C}$ in dendrochronologically dated tree rings opens the entire Holocene for observation. Although there is no means of detecting the past arrival of visible light, the $\gamma$-ray component of cosmic rays produces a potentially detectable amount of ${ }^{14} \mathrm{C}$ (Kocharov et al. 1974). Only the high-energy component of these $\gamma$ rays is effective in producing $(\gamma, \mathrm{n})$ and $(\gamma, 2 \mathrm{n})$ reactions. Whether they are produced in the expanding shell or in the shock waves resulting from the supernova explosion, high-energy or "hard" $\gamma$ rays will arrive after the first thermally initiated light pulse. It is of considerable theoretical interest to know the delay time between arrival of photons and the arrival and peak intensity of the hard $\gamma$-ray component of cosmic-rays. The hard $\gamma$ rays produce neutrons, the thermalized neutrons produce ${ }^{14} \mathrm{C}$ by the ${ }^{14} \mathrm{~N}(\mathrm{n}, \mathrm{p}){ }^{14} \mathrm{C}$ reaction and the resulting ${ }^{14} \mathrm{C}$ reacts to produce ${ }^{14} \mathrm{CO}_{2}$, which participates in the $\mathrm{C}-\mathrm{O}$

\footnotetext{
${ }^{1}$ NSF-Arizona Accelerator Facility for Radioisotope Analysis, Department of Geosciences, The University of Arizona, Tucson, Arizona 85721 USA

2Department of Physics, Nanjing University, Nanjing 210008 China

${ }^{3}$ A. F. Ioffe Physical-Technical Institute, St. Petersburg 194021 Russia

${ }^{4}$ Solar-Terrestrial Environment Laboratory, Nagoya University, Nagoya, Japan
} 
TABLE 1. Historically Observed Supernovas*

\begin{tabular}{ccl}
\hline $\begin{array}{c}\text { Year } \\
(\mathrm{AD})\end{array}$ & $\begin{array}{l}\text { Distance } \\
\text { (light yr) }\end{array}$ & $\begin{array}{l}\text { Remnant } \\
\text { description } \dagger\end{array}$ \\
\hline 185 & $<6,000$ & O, R, S \\
393 & $\sim 1,500(?)$ & O(?) \\
1006 & 4,200 & O, R, X, S \\
1054 & 6,500 & O, R, X, P, D \\
1181 & 28,000 & O, R, X, C, D \\
1572 & 10,000 & O, R, X, S \\
1604 & 26,000 & O, R, X, S \\
\hline
\end{tabular}

*To eliminate nova events, where a star throws off a small part of its mass but may, if nearby in the galaxy, be among the brightest stars, only "new stars" that remained visible for at least six months are included. With the exception of $A D$ 393, all have remnants that have been identified unequivocally. References: Data obtained from Murdin (1985: Table 2) and Stephenson and Clark (1976: 103).

†Key to description: $\mathbf{O}=$ optical remnant; $\mathbf{R}=$ radio remnant; $\mathbf{X}=\mathbf{X}$-ray emitter; $\mathbf{P}=$ known pulsar; $\mathrm{S}=$ shell; $\mathrm{D}=$ disc; $\mathrm{C}=$ compact stellar remnant.

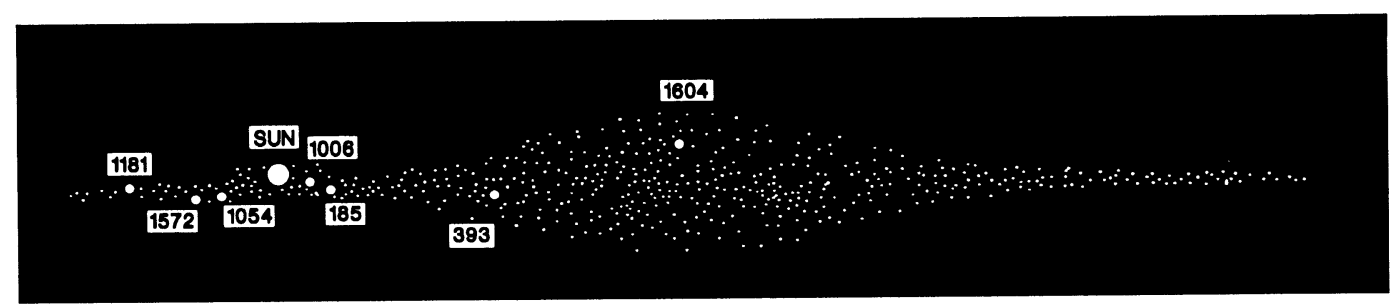

Fig. 1. Positions of historical supernovas (large white dots) in our galaxy. The diameter of our galaxy is ca. 100,000 light yr. SN1006 at 4200 light yr was the closest to Earth. (After Stephenson and Clark (1976).)

cycle; therefore, accurately dated tree rings constitute an ideal natural archive of the arrival of the hard $\gamma$ rays.

Early research at the Ioffe Institute (Kocharov et al. 1974) sought to detect the hard component of supernova-generated $\gamma$ rays from Tycho, Kepler and Cassiopea A. The Tycho supernova was visible for 18 months in $A D$ 1572-1573. Measured $\Delta^{14} \mathrm{C}$ was at a minimum in $\mathrm{AD} 1572$ but increased by 2.0 $\pm 0.8 \%$ during the period from AD 1573 to 1576 , relative to the preceding years, AD 1567-1571. This suggests that $\gamma$ rays producing the $\gamma, \mathrm{n}$ reaction arrived after the visible photo-flash. However, no increase is observed in the single-year, high-precision data of Stuiver and Braziunas (1993).

\section{CHOICE OF SUPERNOVA TO BE STUDIED}

We chose the supernova that was observed in $\mathrm{AD} 1006$ for this study (Table 1, Figure 1). This supernova was the brightest and closest to the solar system ( 4200 light yr) of those observed historically (Table 1). Most information on this supernova comes from Arabic, Japanese and Chinese sources. Although it was too far south and below the horizon to be observed by most northern European observers, the monk Hepidannus of St. Gallen, Switzerland $\left(47^{\circ} 30^{\prime} \mathrm{N}\right)$ observed the star in the constellation Lupus. The main eyewitness source, according to Murdin (1985), was the Egyptian Ali ibn Ridwan, who recorded a list of the exact positions of the planets at the time of first sighting of the supernova. From this list, the exact date of its appearance can be deduced: April 30, 1006. He states that "it was a large nayzak, round in shape and its size two and a half or three times the size of Venus. 
Its light illuminated the horizon and it twinkled a great deal. It was a little more than a quarter of the brightness of the Moon" (Murdin 1985: 15). The radio remnant of SN1006 is shown in Figure 2.

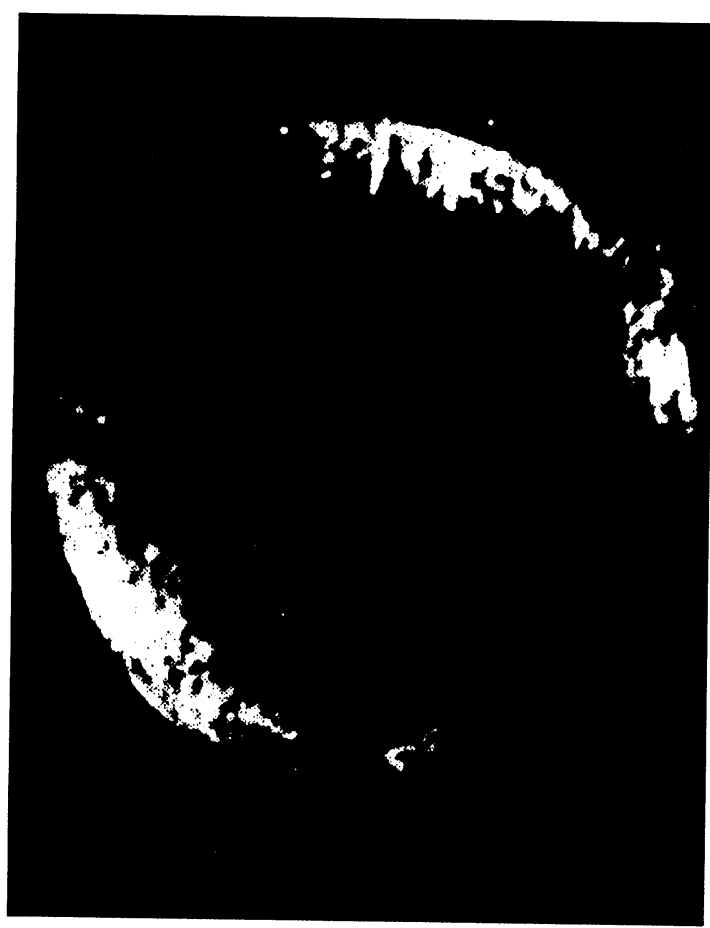

Fig. 2. Radio image of the remnant of SN1006. It appears as a ring, but in three-dimensional perspective it more nearly resembles a shell. This image, obtained through the courtesy of Professor Stephen P. Reynolds, was made with the Very Large Array of the National Radio Astronomy Observatory operated by Associated Universities, Inc., under cooperative agreement with the National Science Foundation. The three points of light are common background extragalactic radio sources (Reynolds and Gilmore 1986).

\section{Production OF ${ }^{14} \mathrm{C}$ BY HARD $\gamma$ RAYS ( $>10 \mathrm{MEV}$ ) IN THE EARTH'S ATMOSPHERE}

Primary $\gamma$ rays entering the Earth's atmosphere will initiate $\mathrm{e}^{+}, \mathrm{e}^{-}$bremsstrahlung cascades. However, to be effective in producing ${ }^{14} \mathrm{C}$ by the reaction ${ }^{14} \mathrm{~N}(\mathrm{n}, \mathrm{p}){ }^{14} \mathrm{C}$, their energy must exceed $10 \mathrm{MeV}$. This limitation is the result of the giant neutron cross-sections between $10 \mathrm{MeV}$ and $40 \mathrm{MeV}$ for $(\gamma, n)$ and $(\gamma, 2 n)$ reactions (IAEA 1987). The cross-sections peak at $23 \mathrm{MeV}$ and are negligible below $10 \mathrm{MeV}$ and above $40 \mathrm{MeV}$. The positrons and negatrons produced in the cascade undergo close encounters with the nuclei primarily of oxygen and nitrogen. These encounters result in production of bremsstrahlung that react with nuclei to produce other pairs, and so on, until eventually the bremsstrahlung energy falls within the giant cross-section, producing neutrons. About $65 \%$ of the neutrons reach thermal energies and are used in producing ${ }^{14} \mathrm{C}$.

The total hard $\gamma$-ray energy from supernova explosions has been estimated to vary between $10^{47} \mathrm{ergs}$ to as high as $10^{50}$ ergs (Berezinskii et al. 1990; Chupp 1976; Lingenfelter and Ramaty 1970).

A distance of 4200 light yr equals $3.97 \times 10^{21} \mathrm{~cm}$. Upon arrival at Earth, the $\gamma$-ray flux would extend over an area of $1.80 \times 10^{44} \mathrm{~cm}^{2}$. A total $\gamma$-ray energy of $10^{49}$ ergs arriving at the top of the atmosphere would yield $1.4 \times 10^{4} \mathrm{ergs} \mathrm{cm}^{-2}$. An estimate of the multiplicity factor resulting from the cascades is beyond the scope of this paper. We accept for purposes of calculation the yield to be about $10^{3}$ neutrons per erg of $\gamma$-ray energy (Lingenfelter and Ramaty 1970). About 65\% of these neutrons are thermalized and available to produce ${ }^{14} \mathrm{C}$ almost quantitatively by the reaction ${ }^{14} \mathrm{~N}(\mathrm{n}, \mathrm{p})^{14} \mathrm{C}$. Thus $1.4 \times 10^{4} \mathrm{ergs} \mathrm{cc^{-2 }}$ e yields $0.9 \times 10^{7}$ thermal neutrons that are available to produce ${ }^{14} \mathrm{C}$. If this flux arrived in one year, the rate of production of ${ }^{14} \mathrm{C}$ would be $0.3 \mathrm{a} \mathrm{cm}^{-2} \mathrm{e}$, or $13 \%$ 
of the steady-state production rate by galactic cosmic rays of $2.4 \mathrm{a} \mathrm{cm}^{-2} \mathrm{e}$. This quantity would not be measurable unless the flux continued for $\geq 4 \mathrm{yr}$.

\section{DESIGN OF THE EXPERIMENT}

We decided to measure samples dating to before and after the historical observance of SN1006. Precisely dated annual samples of sequoia wood from the Big Stump Grove in Sequoia National Park were available for the years $A D$ 995-1020. The Big Stump Grove is at $36^{\circ} 44^{\prime} \mathrm{N}, 118^{\circ} 58^{\prime} \mathrm{W}$, elevation $1845 \mathrm{~m}$ asl. Unfortunately, only a few grams were available for each year. The weight of cellulose extracted was much too small to produce enough benzene for our high-precision, underground scintillation counters (capable of routinely obtaining $\pm 2 \%$ or better precision), so it was necessary to use the NSF-Arizona AMS Laboratory, with which $\pm 5 \%$ analyses could be obtained on one target at the time of dating. Consequently, we planned to measure three targets for each year from AD 10031020 , to obtain an expected precision of $\pm 2.9 \%$. Unfortunately, during our two measurement periods only a $\pm 7 \%$ precision was obtainable for one graphite target, meaning that four graphite targets were required to obtain $\pm 3.5 \%$. Sample preparation techniques were essentially the same as described in Damon et al. (1992).

\section{RESULTS}

The data are presented in Table 2 and plotted in Figure 3. $\Delta^{14} \mathrm{C}$ is the age and isotopic fractionationcorrected value calculated as \%o difference from the accepted NIST HOxI standard sample value (Stuiver and Polach 1977). It increases after AD 1009, 3 yr after the visual observation of SN1006, by $c a .9 .5 \%$. $\Delta^{14} \mathrm{C}$ remains high for $c a .9 \mathrm{yr}$, after which the values are indistinguishable from pre1010 values. If we compare the $7 \mathrm{yr}$ before 1009 (average $\Delta^{14} \mathrm{C}=-20.6 \pm 3.7$ (s.d.)\%o) with the $9 \mathrm{yr}$

TABLE 2. Preliminary Results on Sequoia Wood from Time of SN1006

\begin{tabular}{ccccc}
\hline $\begin{array}{c}\text { Year } \\
(\mathrm{AD})\end{array}$ & $\begin{array}{c}\Delta^{14} \mathrm{C} \\
(\% 0)\end{array}$ & $\begin{array}{c}\sigma^{*} \\
(\%)\end{array}$ & $\begin{array}{c}\text { Number of } \\
\text { analyses }\end{array}$ & $\begin{array}{c}\delta^{13} \mathrm{C} \\
(\%)\end{array}$ \\
\hline 1003 & -26.6 & \pm 4.0 & 3 & -18.6 \\
1004 & -14.6 & \pm 3.9 & 4 & -18.9 \\
1005 & -18.7 & \pm 4.0 & 3 & -19.0 \\
1006 & -21.8 & \pm 4.0 & 3 & -18.7 \\
1007 & -19.3 & \pm 3.7 & 4 & -18.9 \\
1008 & -21.1 & \pm 3.4 & 5 & -19.3 \\
1009 & -22.2 & \pm 3.8 & 4 & -19.9 \\
1010 & -15.2 & \pm 3.3 & 5 & -19.5 \\
1011 & -10.0 & \pm 3.5 & 5 & -19.7 \\
1012 & -17.1 & \pm 3.3 & 5 & -19.1 \\
1013 & -11.1 & \pm 3.2 & 5 & -19.1 \\
1014 & -16.7 & \pm 3.0 & 6 & -18.8 \\
1015 & -11.8 & \pm 4.1 & 3 & -19.3 \\
1016 & -18.3 & \pm 3.4 & 5 & -18.8 \\
1017 & -17.7 & \pm 4.6 & 4 & -19.4 \\
1018 & -12.6 & \pm 3.2 & 5 & -19.3 \\
1019 & -20.3 & \pm 3.8 & 3 & -18.6 \\
1020 & -21.5 & \pm 3.9 & 3 & -19.3 \\
\hline
\end{tabular}

*Standard deviation for $\mathrm{N}$ separate analyses 




Fig. 3. Measurements of $\Delta^{14} \mathrm{C}$ (age and stable isotope-corrected deviations from a standard value). Precision is $\pm 1 \sigma$. The curve is a six-box carbon model with sedimentary sink fit to the data, assuming the $\gamma$-rays $(>10$ $\mathrm{MeV}$ ) arrive as a pulse immediately after $\mathrm{AD}$ 1009. A pulse lasting $2 \mathrm{yr}$ provides an equally good fit to the data.

from 1010 to 1018 (average $\Delta^{14} \mathrm{C}=-14.5 \pm 3.2$ (s.d.)\%o), $\mathrm{t}=3.30$ for the Student's $\mathrm{t}$ test and the difference is highly significant at $99.6 \%$ confidence.

Next we use a six-box carbon-cycle model modified after Bacastow and Keeling (1973), assuming the $\gamma$-ray pulse occurs during one year, to obtain a best fit to the data (Fig. 3). The model includes a stratosphere, troposphere, short- and long-lived biosphere, a mixed ocean layer, deep sea and oceanic sedimentary sink. If the radiation path length is $63 \mathrm{~g} \mathrm{~cm}^{-2}$, then the number of radiation path lengths needed to reduce $1 \mathrm{GeV} \gamma$ rays to below the critical value, $10 \mathrm{MeV}$, is 67.7 or $422 \mathrm{~g} \mathrm{~cm}^{-2}$, corresponding to an altitude that is well within the troposphere. In order to reach the critical value within the stratosphere, a $\gamma$ ray must have an energy $<50 \mathrm{MeV}$. Since most of the $\gamma$ rays have energies in the range of $70 \mathrm{MeV}$ to $10 \mathrm{GeV}$ (Berezinskii et al. 1990: 307), the bulk of ${ }^{14} \mathrm{C}$ production will be in the troposphere. Consequently, we chose $20 \%$ production in the stratosphere and $80 \%$ in the troposphere. We assume the $\gamma$ rays arrive in a one-year pulse. The best fit curve is shown in Figure 3. Only 4 of 18 measurements fall outside of $1 \sigma$ and none fall outside $2 \sigma$ from the curve.

To achieve the best fit, we had to change the ${ }^{14} \mathrm{C}$ production rate from $2.4 \mathrm{a} \mathrm{cm}^{-2} \mathrm{~s}$ to $6.0 \mathrm{a} \mathrm{cm}^{-2} \mathrm{~s}$, or a factor of 2.5 for one year. This requires a total production of thermalized neutrons resulting from primary supernova $\gamma$ rays of $17.1 \times 10^{7} \mathrm{n} \mathrm{cm}^{-2}$, implying that the input of $11.3 \times 10^{4} \mathrm{ergs} \mathrm{cm}^{-2} \mathrm{e}^{-}$ ray energy $(>10 \mathrm{MeV})$ was $1 \times 10^{50} \mathrm{ergs}$, which is within the estimated range for such events.

\section{ConClusion}

The duration of the ${ }^{14} \mathrm{C}$ increase event is limited by the carbon cycle. The data requires a sharp rise limiting the duration to, at most, three years. The duration is also limited by the decay, which is due to equilibration with the biosphere and mixed layer of the ocean, followed by a much slower equilibration with the deep sea. The total supernova $\gamma$-ray energy $(>10 \mathrm{MeV}), 1 \times 10^{50} \mathrm{ergs}$, is not unreasonable. A delay of three years after the visual sighting of SN1006 was not anticipated. However, dendrochronologists responsible for the chronology of the sequoia tree-ring samples are confident that the chronology is accurate to one year (see Acknowledgments below). 
Stuiver and Braziunas (1993) have published high-precision single-year $\Delta^{14} \mathrm{C}$ data for the period $\mathrm{AD}$ 1510-1954. Two supernovas occurred during that time, SN1572 observed by Tycho Brahe and SN1604 observed by Johannes Kepler, both at greater distances from Earth than SN1006. If SN1572 $(10,000$ light yr) produced the same $\gamma$-ray energy $(>10 \mathrm{MeV})$ as SN1006, the expected increase would have been $c a .1 .5 \%$ and $0.2 \%$ for SN1604 (26,000 light yr). It is not surprising that a measurable increase is not observable in the single-year data relevant to these two supernovas.

If a series of very large solar flares were to occur over a 2-yr period, a signal such as in Figure 3 could occur. However, in the 454-yr record of Stuiver and Braziunas (1993) we observe only one other event of similar magnitude and duration as that in Figure 1. It seems unlikely that such a rare event would fortuitously occur $3 \mathrm{yr}$ after SN1006.

\section{ACKNOWLEDGMENTS}

We are grateful to Malcolm Hughes, Peter Brown and Ramzi Touchan of the University of Arizona Laboratory of Tree-Ring Research for providing wood samples for this research accurate to the year. We are also grateful to our colleagues in the University of Arizona AMS Laboratory, in particular George Burr, Larry Toolin and Warren Beck, for their help in measuring the samples, and to Professor Stephen P. Reynolds of North Carolina State University for making available the radio image of SN1006. This work was supported by NSF grants EAR-882292 and ATM-9221218 and the State of Arizona.

\section{REFERENCES}

Berezinskii, V. S., Bulanov, S. V. and Dogiel, V. A. 1990 Astrophysics of Cosmic Rays. Amsterdam, North-Holland: $534 \mathrm{p}$.

Bacastow, R. and Keeling, C. D. 1973 Atmospheric carbon dioxide and radiocarbon in the natural carbon cycle: II. Changes from A.D. 1700 to 2070 as deduced from a geochemical model. In Woodwell, G. M. and Pecan, E. V., eds., Carbon and the Biosphere. Proceedings of the 24th Brookhaven Symposium in Biology, Upton, New York: 87-135.

Chupp, E. L. 1976 Gamma-Ray Astronomy. Bingham, Massachussets, Reidel Publishing Co.: 317 p.

Damon, P. E., Burr, G., Cain, W. J. and Donahue, D. J. 1992 Anomalous 11 -year $\Delta^{14} \mathrm{C}$ cycle at high latitudes? Radiocarbon 34(2): 235-238.

International Atomic Energy Agency (IAEA) 1987 Handbook on Nuclear Activation Data. IAEA Technical Report Series 273. Vienna, IAEA: 811 p.

Kocharov, G. E., Dergachev, V. A., Sementsov, A. A., Romanova, E. N., Rumiantsev, S. A., Malanova, N. S. and Svezhentsev, I. U. S. 1974 Concentration of radiocarbon in tree-rings. In Proceedings of the 5th All-Union Meeting on Astrophysical Phenomena and Radiocarbon, Tbilisi. (Translated by Peterson, G. M., Center for Climatic Research, Institute for Environmental Studies, Madison, University of Wisconsin): 47-60.

Lingenfelter, R. E. and Ramaty, R. 1970 Astrophysical and geophysical variation in C-14 production. In Olsson, I. U., ed., Radiocarbon Variations and Absolute Chronology. New York, John Wiley \& Sons: 513-537.

McHargue, L. R., Damon, P. E. and Donahue, D. J. 1995 Enhanced cosmic-ray production of ${ }^{10} \mathrm{Be}$ coincident with the Mono Lake and Laschamp geomagnetic excursions. Geophysical Research Letters 22: 659-662.

Murdin, P. 1985 Supernovae. 2nd ed. Cambridge, Cambridge University Press: 185 p.

1990 End in Fire: The Supernova in the Large Magellanic Cloud. Cambridge, Cambridge University Press: $251 \mathrm{p}$.

Raisbeck, G. M., Yiou, F., Bourles, D., Lorius, C., Jouzel, J. and Barkov, N. I. 1987 Evidence for two intervals of enhanced ${ }^{10} \mathrm{Be}$ deposition in Antarctic ice during the last glacial period. Nature 326: 273-277.

Reynolds, S. P. and Gilmore, D. M. 1986 Radio observations of the remnant of the supernova of A.D. 1006. I. Total intensity observations. Astronomical Journal 92: 1138-1144.

Stephenson, F. R. and Clark, D. H. 1976 Historical supernovas. Scientific American 234: 100-107.

Stuiver, M. and Braziunas, T. F. 1993 Sun, ocean, climate and atmospheric $\mathrm{CO}_{2}$ : An evaluation of causal and spectral relationships. The Holocene 3(4): 289-305.

Stuiver, M. and Polach, H. 1977 Discussion: Reporting of ${ }^{14} \mathrm{C}$ data. Radiocarbon 19(3): 355-363. 